[Agr. Biol. Chem., Vol. 27, No. 2, p. 99 102, 1963]

\title{
Artificial Food for Oak-Silkworm Raising
}

\author{
By Toshifumi Fukuda and Yoshikichi Higuchi \\ The Sericultural Experiment Station, Tokyo
}

Received August 1, 1962

\begin{abstract}
Oak-silkworms (Anthereae pernyi) were reared from hatching to the adult stage on a diet consisting of powder of dry leaves of oak trees (Quercus dentata T.), 'kinako' (powder of parched soy bean), sucrose, agar-agar, sodium dehydroacetate as an antiseptic, and water. Among 100 newly hatched oak-silkworms reared on the diet, 23 spun their cocoons. The weight of the cocoon fibres spun by one worm and the number of the eggs laid down by one moth were $0.34 \mathrm{~g}$ and 203 , respectively, on the average.
\end{abstract}

Fukuda, Suto and Higuchi (1960) ${ }^{1)}$ pointed out that it is possible to rear mulberry silkworms (Bombyx mori) from hatching to the adult stage on an artificial food. This experiment gave us many informations on the rearing of phytophagous insects, especially of the silk-producing worms, on artificial food. Recently Fukuda, Higuchi and Matsuda $(1961)^{2)}$ reared also eri-silkworms (Philosamia cynthia ricini) on an artificial food. The eri-silkworms fed on artificial food are by no means inferior to those fed on fresh leaves of castor-oil plant (Ricinus communis), a proper food for this insect, and produce cocoon fibres and lay eggs in rather a better yield. This paper deals with the rearing of the oaksilkworm (Anthreae pernyi), whose place of origin is China, on artificial food. There are no reports up to now regarding the oaksilkworm which has been reared on artificial food. Raising of the oak-silkworm on artificial food may be of importance industrially, because the fibres spun by oak-silkworms are still of commercial value.

1) T. Fukuda, M. Suto and Y. Higuchi, Nature, 187, 669 (1960); XI Intern. Congr. Entomology Vienna (1960) Sym. 'Insect Chemistry' P. 163.

2) T. Fukuda, Y. Higuchi and M. Matsuda, This Journal, 25, 417 (1961).

\section{PREPARATION OF DIET AND OAK-SILKWORM RAISING}

1) Preparation of the Artificial Food. The composition of the artificial foods is given in Table $I$. To the hot solution containing agar-agar, sucrose and antiseptic were added the powdered leaves of oak trees (Quercus dentata T.) and the 'kinako' (a powder of parched soy bean). The mixture was stirred with a glass rod, kept at room temperature, and placed in a refrigerator. The water content was 75 per cent in the diet devised for rearing the younger larva, and 70 per cent in the diet for the grown larva. The amounts of sodium dehydroacetate which was added as an antiseptic to the diet described in Table I were $54 \mathrm{mg}$ in the diet for the younger larva, and $42 \mathrm{mg}$ in the diet for the grown larva. For preparing the dry leaf powder leaves picked from oak trees

TABle I. The Composition of The ARtificial FOOD

Diet for younger Diet for grown oak-silkworms, oak-silkworms,

Composition from the 1st. from the 4th. stage stage to the 3rd. to the end of the stage 5 th. stage

Powdered of dry leaves of the oak trees $6.0 \mathrm{~g}$ $6.0 \mathrm{~g}$

' Kinako' (a powder of parched soy bean)

$1.0 \prime \prime$

$1.0 \prime \prime$

Sucrose

$1.0 \prime \prime$

$1.0 \prime \prime$

Agar-agar

$1.0 \prime \prime$

$1.0 \prime \prime$

Antiseptic solution*

$27 \mathrm{ml}$

$21 \mathrm{ml}$

* The antiseptic solution was prepared by dissolving $2 \mathrm{~g}$ of sodium dehydroacetate in $1 \boldsymbol{l}$ of water. 
(Quercus dentata T.) on the first ten days of May, 1961, were dried at below $60^{\circ} \mathrm{C}$ under air-blast, pulverized and screened through an 80-mesh sieve.

2) Oak-silkworm Raising. A piece of paraffinpaper was placed in the bottom of a petri dish. The artificial food prepared for the rearing of younger oak-silkworms was placed on the paraffin-paper, then the newly hatched worms were placed on it, and the dish was covered with a lid. The oak-silkworms were reared on the artificial food until the end of the third stage. The fourth instar was removed from the petri dish to a wooden box whose bottom is covered with wire-netting, and reared on the artificial food prepared for the grown oak-silkworm until the end of the fifth stage. The petri dish and the wooden box containing the oak-silkworms were each placed in an cabinet kept at $26^{\circ} \mathrm{C}$ and $70 \sim 80$ per cent humidity. The number of the oak-silkworms used for the present study was 100 . The artificial food was cut in slices $0.1 \sim 1 \mathrm{~mm}$ thick. The slices were fed to the oak-silkworms twice daily.

\section{RESULTS AND DISCUSSION}

Results on larval raising, cocoon fibres and eggs of the oak-silkworms reared on artificial food are given in Table II. Among 100 newly hatched oak-silkworms, 23 spun their co-

TABLE II. RESUltS ON LARVAL RAISING, COCOON FIBRE AND EGGS OF THE OAK-SILKWORM RE:ARED ON THE ARTIFICIAL FOOD

Matters of investigation

Number of newly hatched oak-silkworms used for the experiments

Number of cocoon produced

Larval period (days)

Pupal period (days)

Weight of oak-silkworm per one worm (g)

Newly hatched larva

Newly moulted larva (2nd.)

(3rd.)

(4th.)

(5th.)

Larva at the most voracious stage

Matured larva

Pupa

Weight of cocoon fibre produced by one larva (mg)

Number of eggs laid down by one moth coons. The mortality of the oak-silkworms was remarkably high after the third stage. A similar phenomenon was recently recognized by W. R. Harvey (1962) (private communication). The body of the oak-silkworm suffering from a disease was tinged with yellow, and the circumference of breathing holes assumed a blackish brown color. The body of the oak-silkworms died of illness was quite black. Generally speaking, the oak-silkworm in an oak wood crawls about actively from branch to branch to eat fresh leaves, but once the insect is reared on artificial food in a petri dish, the habit stated above becomes so weak that even the insect after the fourth stage never crawls out from the petri dish. Fig. 1 shows the oak-silkworms at the sixth day of the fifth stage, three days before spinning, eating the artificial food. Fig. 2 shows also the matured larva, the pupa, the moth, the cocoon and the eggs obtained by using the artificial food. The time between hatching of oak-silkworm and spinning of a cocoon was 29 45 days. Though the body weight of the oak-silkworm reached $14.5 \mathrm{~g}$ ( $16 \mathrm{~g}$ maximum) at the most voracious stage of the fifth instar, the weight of the cocoon fibre spun was only $0.39 \mathrm{~g}(0.48 \mathrm{~g}$ maximum $)$ by the female and was $0.28 \mathrm{~g}$ ( $0.46 \mathrm{~g}$ maximum) by the male. The number of the eggs laid by one moth was 203 on the average. The present study points out that it is possible to rear oak-silkworms from hatching to the adult stage on the artificial food whose main constituent is the powder of dry leaves of oak (Quercus dentata T.), but the present diet leaves much room for improvement. As the fresh leaves of the Quercus acutissima $\mathrm{C}$., the Quercus serrata $\mathrm{T}$. and Quercus myrsinaefolia B. which belong to the same family as the Quercus dentata $\mathbf{T}$. are also recognized generally as proper food for this insect; several kinds of artificial diet whose main constituent 


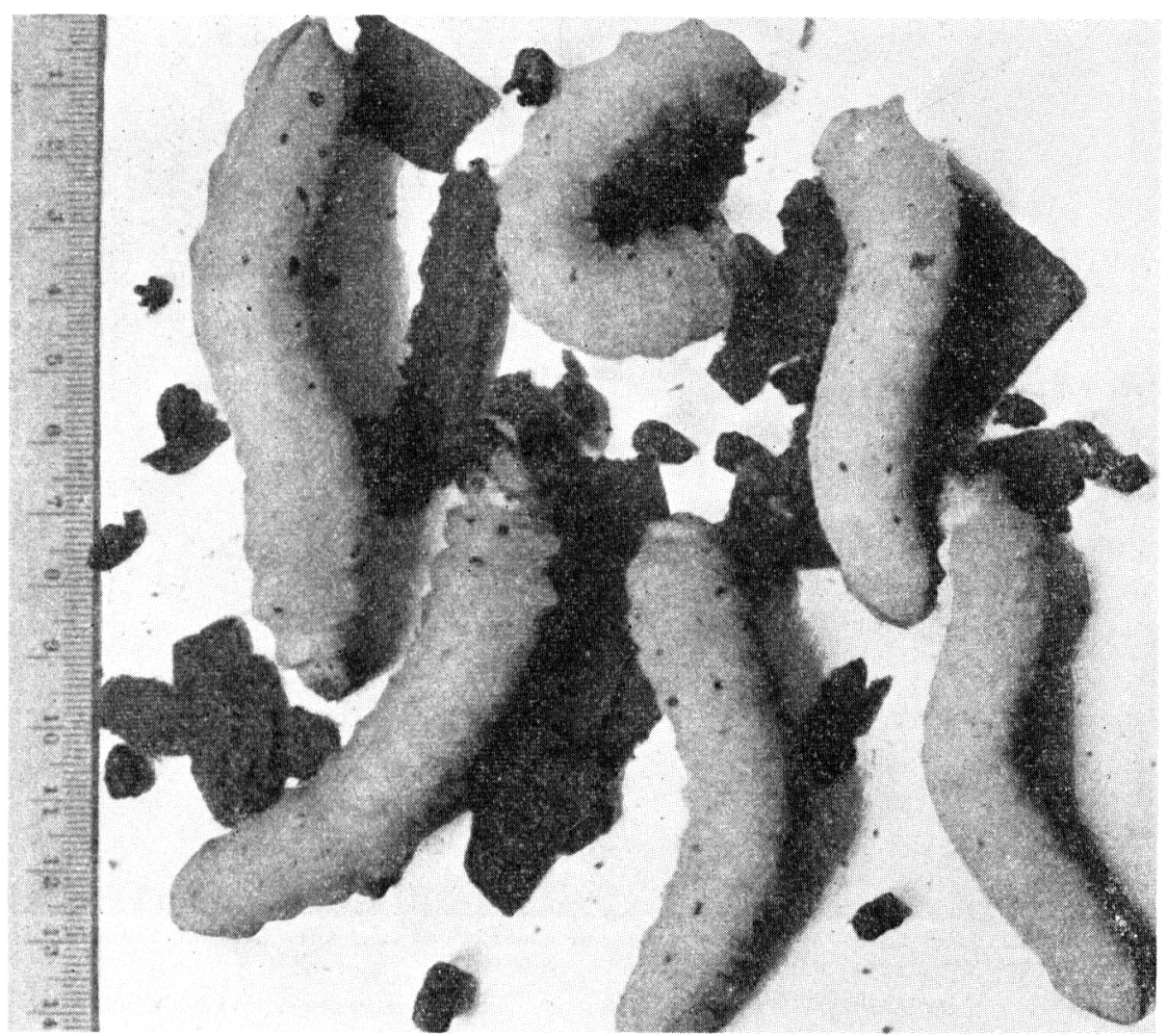

FIG. 1. Oak-silkworms Eating Artificial Food.

was each of dry leaf powder of these plants were prepared. Of course, the oak-silkworms reared on these diets spun their cocoons.

We have succeeded in rearing mulberry silkworms (Bombyx mori) and eri-silkworms (Philosamia cynthia ricini) on artificial foods, but the raising of these silkworms on artificial foods might be rather easy, because these insects have been domesticated indoors. Since oak-silkworms are wild, a large scale raising of oak-silkworms has been carried out outdloors as well as in oak wood (Quercus accutissima C.). The possibility at present to rear oak-silkworms indoors as well as on artificial food seems to be of a significance. Speaking of wild silkworms, we succeeded also recently in rearing the Antheraea yamamai on an artificial food from hatching to the second day of the fifth stage, and the Samia cynthia on artificial food from hatching to the end of the fourth stage.

\section{SUMMARY}

1) Oak-silkworms (Anthereae pernyi) were reared from hatching to the adult stage on

$\begin{array}{lcc} & \begin{array}{c}\text { Diet for } \\ \text { younger larvae }\end{array} & \begin{array}{c}\text { Diet for } \\ \text { grown larvae }\end{array} \\ \begin{array}{c}\text { Powdered of dry leaves } \\ \text { of oak trees }\end{array} & 6.0 \mathrm{~g} & 6.0 \mathrm{~g} \\ \begin{array}{c}\text { Kinako' (a powder of } \\ \text { parched soy bean) }\end{array} & 1.0 & 1.0 \\ \begin{array}{l}\text { Sucrose } \\ \text { Agar-agar }\end{array} & 1.0 & 1.0 \\ \begin{array}{l}\text { Sodium dehydroacetate } \\ \text { as an antiseptic }\end{array} & 1.0 & 1.0 \\ \text { Water } & 54 \mathrm{mg} & 42 \mathrm{mg} \\ & 27 \mathrm{ml} & 21 \mathrm{ml}\end{array}$




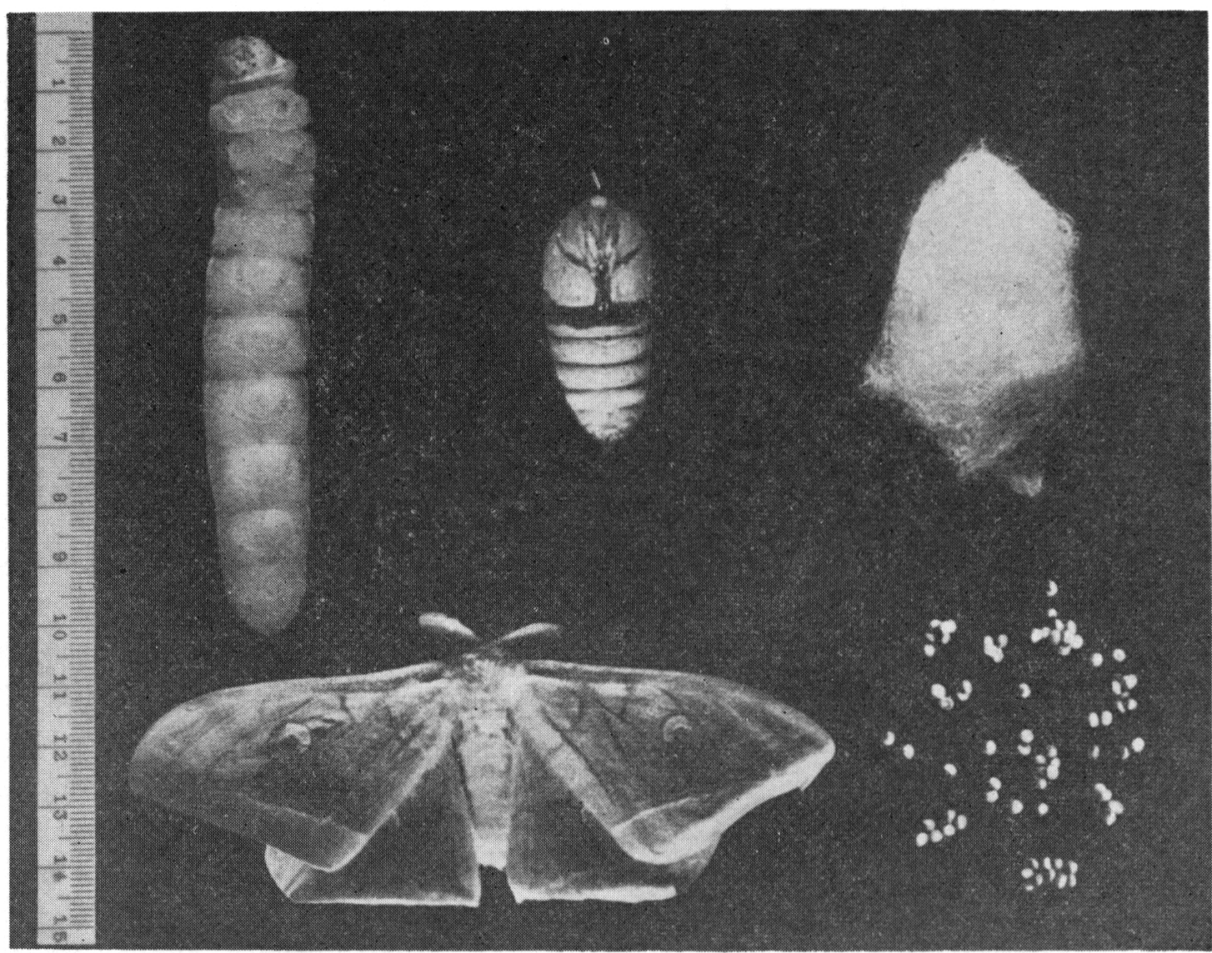

FIG. 2. Matrured Larva, Pupa, Moth, Cocoon and Eggs Obtained by Using Artificial Food.

an artificial food. The composition of the artificial foods devised is as before page:

2) Among 100 newly hatched oak-silkworms, 23 spun their cocoons.

3) The mortality of the oak-silkworms was remarkably high after the third stage.

4) The weight of the cocoon fibres spun by one oak-silkworm was $0.34 \mathrm{~g}$ on the average.

5) The number of the eggs laid down by one moth was 203 on the average.
Acknowledgement. We wish to thank Mr. Sigeo Tanaka (The Nagano Prefectural Sericultural Experiment Station, The Matsumoto Branch Station) and Mr. Kiyoshi Asano (The Sericultural Experiment Station, The Chubu Branch Station) who presented us eggs of oak-silkworms, and Mr. Yoshio Kobayashi and Mr. Tamotsu Kushida (The Forest Experiment Station, The Asakawa Branch Station) who advised us on the collection of oak leaves. 